RASĀYAN J. Chem.

Vol. 11 | No. 3 |1007 - 1017 | July - September | 2018

ISSN: 0974-1496 | e-ISSN: 0976-0083 | CODEN: RJCABP

http://www.rasayanjournal.com

http://www.rasayanjournal.co.in

\title{
THE ROLE OF OXYGEN IN THE MAIN FERMENTATION OF BEER IN CONCENTRATION OF 6, 8 AND 10 MG/L
}

\author{
Arsim Elshani ${ }^{1}$, Kastriot Pehlivani ${ }^{2, *}$, Bakir Kelmendi ${ }^{1}$ and Nexhdet Shala ${ }^{1}$ \\ ${ }^{1}$ Department of Food Technology, University HAXHI ZEKA, Peja-30000, Kosovo \\ ${ }^{2}$ Department of Beer Production, J.S.C. "Birra Peja", Peja-30000, Kosovo \\ *E-mail : kastriot.p@birrapeja.com
}

\begin{abstract}
Oxygen represents to fermentation, both a friend and an enemy. As it is much needed especially during the beginning of fermentation process, should also be completely eliminated even its contact with the beer during transfer from one tank to another of the finished beer and during packaging in bottles, cans or barrels. It is very important to understand when it is needed, and vice versa. And where aeration or oxygenation process is necessary as for example during the beginning of fermentation should be a wort aeration or oxygenation is allowed within certain criteria. The taste stability of beer remains a key point during beer processing in a brewery. Hundreds ingredient, form a complex matrix of beer and of course, chemical reactions lead to changes in the composition of beer as well as the characteristics associated with taste and smell. Oxygen presence among the many ways of decomposition, in particular, the taste quality of the beer is damaged, the volatility of iso - alpha - acids and derivatives that are used as key agents in beer distressful.
\end{abstract}

Keywords: oxygen, beer, extracts, fermentation, long life.

CRASĀYAN. All rights reserved

\section{INTRODUCTION}

In the stage of fermentation of a new beer, after giving the oxygen in amounts ranging by 6,8 , and then with $10 \mathrm{mg} / \mathrm{l}^{2}$ Was taken for analysis of different beers with extract $15 \%, 13 \%$ and $11.3 \%$, , and comparisons are made with results obtained through the beer reference. As objective we had given the influence of oxygen in the fermentation of beer, to acquire a taste for beer and good flavor to me. ${ }^{4,5}$

We were cooling stage and filling the wort fermentation tank for the cooling action is followed and that the wort cooling time.

The objective has been developed or cooking process and the fermentation according to criteria from the literature data of known offenders.

As we mature beer maturation process is followed, starting awakening of beer and $\mathrm{CO}_{2}$ saturation. ${ }^{3}$ The main objective has been, or is in possession of the proper removal of the precipitate of the yeast out of a tank and $\mathrm{CO}_{2}$ saturation.

\section{EXPERIMENTAL}

\section{Material and Methods}

Wort aeration

Wort must contain oxygen when yeast injection is done. During aerobic respiration of yeast is released more energy for sugar glycolize than in anaerobe process. Yeast needs a lot of energy for its growing in satisfied levels. Wort aeration is done for two different reasons:

- To separate the cold turbidity particles, and

- To supply with oxygen the wort for fermentation.

If the cold wort contains air in form of bubbles at the moment of transfer to the fermentation tank, cold turbidity formed during the cooling process will rise to the surface from caused by air bubbles and then removed. Wort must contain 6-8 $\mathrm{mg}$ oxygen/l at the moment of inoculation.

Rasayan J. Chem., 11(3), 1007-1017(2018)

http://dx.doi.org/10.31788/RJC.2018.1133087

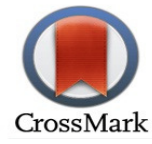


If the wort goes under removing of cold turbidity, an amount of oxygen will be lost, therefore should be fixed the amount of oxygen before the fermentation process started. Many breweries add oxygen and do the inoculation of yeast in two different actions determined in time. This means that a starting tank is used only for removing of cold turbidity and then, afterward is fixed the content of wort oxygen and wort is transferred to the fermentation tank where is done the inoculation of yeast. There is much equipment that can do the sterilization of air needed for oxygenation of wort. Equipment does the sterilization of air through filters and then do the mixing of air with wort. If the air contains $20 \%$ oxygen, the air volume should be 5 times more than the volume of pure oxygen that should be injected.

In the presence of overdose of oxygen, yeast oxidizes all fermentable sugars and all organic acids, aldehydes, alcohols to water and carbonate dioxide. If the oxygen is absent, the oxygenation stops and start the formation of alcohol and water. In the presence of oxygen the breathing is aerobic and in the absence of oxygen, the process is anaerobic.

High gravity worts need more yeast for fermentation; therefore need more oxygen but the high gravity make it more difficult the digestion of oxygen. The wort boiling release the oxygen present in the wort, therefore, aeration is preferred before the start of fermentation.

To oxygenize the wort can be used the in-Line equipment. This equipment makes possible the uniform oxygenation of wort. This equipment can be a part of "a closed system" which enables better hygienic conditions.

This equipment saves the time, too; wort is transferred to the fermentation tank and is oxygenized at the same time. Wort enters through feeding pipe from the cooler and is transferred to the tank for fermentation. Oxygen can make bubbles during crossing through the wort when it enters the fermenter. This makes possible maximal oxygen intake for wort. This device can be sterilized easily throughout boiling and this should not damage its usage.

There should not do the aeration when the wort is hot or warm. Aeration of hot wort can lead to a chemical reaction of oxygen with different ingredients of wort. After some time these ingredients (if aerated hot) will release the atomic oxygen to beer, and can oxidize alcohols and hops, so, can release taste and aroma like a wet card or cherry taste. The most appropriate temperature used to avoid the oxygenation of wort is $8^{\circ} \mathrm{C}$.

\section{Yeast}

Yeast is the most important factor in the determination of fermentation quality. ${ }^{9}$ However there are some yeast types that react very good in "open" fermentation (where the fermentation tank is open) without releasing bed aromas or smell. But, even for these types of yeast, aeration or contact with oxygen after fermentation can lead to beer spoilage. During filling in another fermentation tank or in the barrel, it is very important to avoid shake or turbulence and excessive aeration. Inoculation of healthy yeast should be done in a starter which fulfills the required conditions of fermentation. Wort, in the beginning, is cooled in fermentation temperature and afterward is aerated to ensure the sufficient oxygen which is necessary for yeast growing and reproduction. After the fermentation is finished, beer must be protected from oxygen intake to avoid oxidation and spoilage.

Oxygen supply for yeast during inoculation is a decisive point to ensure a strong and full fermentation.

\section{Detection Method}

\section{Determination of Oxygen Content}

Determination of oxygen content is done for finished beer in glass bottles, PET bottles, and cans. The measurement of oxygen content in finished and bottled beer is done with Digox. The way of measurement and device usage are given in details in EBC. ${ }^{4,3}$

\section{Determination of $\mathbf{p H}$}

$\mathrm{pH}$ determination is done with $\mathrm{pH}$ electronic meter. will be done via electronic $\mathrm{pH}$ meter. For this intent in a glass is put a small amount of beer and inside beer is put the electrode of $\mathrm{pH}$ meter. Waited for some seconds till the value is stabilized and in this way is done for each sample. After each measurement, the electrode is cleaned. ${ }^{4,7}$ 


\section{Acidity Determination}

For this determination, an amount of beer is put in a glass and the glass on the magnetic mixer till the complete release of $\mathrm{CO}_{2}$, because its presence can lead to incorrect acidity values. Then $10 \mathrm{ml}$ of beer is put in a conical vessel and is added $50 \mathrm{ml}$ of distilled water and two drops of phenolphthalein. Titration is done with $\mathrm{NaOH} 0.1 \mathrm{~N}$ solution. At the moment that the color of the solution in the conical vessel is changed to pink, titration is stopped and is read the value in the burette. ${ }^{4,5}$

\section{Determination of Bitter Substances}

This determination is done through a spectrophotometer, Agilent type. In the beginning, are done following treatments. $5 \mathrm{ml}$ beers are taken with a pipette and are added $10 \mathrm{ml}$ isooctane on it and $0.25 \mathrm{ml}$ $\mathrm{HCl} 0.6 \mathrm{~N}$. This mixture is put in the mixer for $15 \mathrm{~min}$. Then the mixture is put in two epruvetes and separated in two equal amounts. Epruvetes are put in a centrifuge for $5 \mathrm{~min}$. With a lot of care, the upper parts of the mixture from epruvetes are put in caveats. Beforehand is made the calibration of the spectrophotometer with distilled water, then cyveta is put in it, and is read the given value in the device for the $275 \mathrm{~nm}$ wave length. The given value is multiplied for 50 and in this way, we get the result for determining bitter substances. ${ }^{7}$

\section{Color Determination}

For this determination is used a spectrophotometer, again, Agilent type. It is taken e certain amount of beer and is put in a mixer till the entire remove of foam. Firstly is made the calibration of the device with distilled water and then is put beer in cyvete carefully. In device is read the value of absorbance for wave length of $450 \mathrm{~nm}$. The gained value is multiplied with $25 .{ }^{4,8}$

\section{$\mathrm{CO}_{2}$ Determination}

To do this determination is used the device for $\mathrm{CO}_{2}$ measuring, Hoffman's type. For this intention, it is taken a sample bottle and is put in the determined place of the device, and is read the given value of pressure. Then is a measured temperature with the thermometer and independence of these two given parameters, temperature, and pressure, is calculated the value of $\mathrm{CO}_{2}$ content. ${ }^{5}$

\section{Air Determination}

For this intention is used the device for $\mathrm{O}_{2}$ Hoffman's type. After the pressure is read, carefully is opened the valve which enables beer to pass the space where is $\mathrm{KOH}$ solution. At the moment that is stabilized the value, it is taken that value as definitive. ${ }^{3,4}$

\section{Balling Determination}

For this intention is used the device Beer Analyzer, Anton Paar type. For this determination is passed beer in a given cylinder for each sample. Inside the cylinder is put soda for measuring and only when the values are stabilized is read the result and the temperature. The correcting of Balling value is done for temperature $\mathrm{t}=20^{\circ} \mathrm{C} .^{4}$

\section{Alcohol Determination}

This determination is done by beer distillation.

For this reason, is taken $150 \mathrm{ml}$ beer from which is removed $\mathrm{CO}_{2}$ in a mixer and is passed to a balloon glass of $250 \mathrm{ml}$. In the distillation device is done the process of distillation carefully. The distillate is taken in a cylinder. After the process of distillation is finished, the distillate is left to be cooled and is put inside the cylinder the alcoholmeter. The process is finished and the final result of alcohol content is read. ${ }^{4}$

\section{RESULTS AND DISCUSSION}

Table-1 provides a summary of the analysis for the green beer, the amount of oxygen $6 \mathrm{mg} / 1$ in the main fermentation, in order to determine the appropriate quantity of beer fermentation with yeast extract $15 \%$, $13 \%$ and $11.3 \%{ }^{1}$. We note a lower value instance of rapid fermentation and apparent degree of fermentation. 
RASĀYAN J. Chem.

Vol. 11 | No. 3 |1007 - 1017 | July - September | 2018

Table-1: Analysis of green beer with supplying oxygen in amounts of $6 \mathrm{mg} / \mathrm{l}$.

\begin{tabular}{|c|c|c|c|c|c|c|}
\hline $\begin{array}{c}\text { The basic } \\
\text { extract }\end{array}$ & Really extract & $\begin{array}{l}\text { Visible } \\
\text { extract }\end{array}$ & $\begin{array}{l}\text { The rapid rate } \\
\text { of } \\
\text { fermentation }\end{array}$ & $\begin{array}{l}\text { The apparent } \\
\text { rate of } \\
\text { fermentation }\end{array}$ & Alcohol & $\mathrm{pH}$ \\
\hline$\%$ & $\%$ & $\%$ & $\%$ & $\%$ & $\%$ & $\%$ \\
\hline 15.2 & 5.22 & 3.31 & 60.8 & 75.54 & 5.7 & 4.45 \\
\hline 13.3 & 4.99 & 2.98 & 61.51 & 78.8 & 5.6 & 4.51 \\
\hline 11.5 & 3.25 & 1.86 & 71.17 & 79.8 & 5.1 & 4.38 \\
\hline
\end{tabular}

Table-2: Analysis of Finished Beer with Oxygen Amounts of 6 mg / 1.

\begin{tabular}{c|c|c|c|c|c|c|c|c}
\hline $\begin{array}{c}\text { The } \\
\text { basic } \\
\text { extract }\end{array}$ & $\begin{array}{c}\text { Really } \\
\text { extract }\end{array}$ & $\begin{array}{c}\text { Visible } \\
\text { extract }\end{array}$ & $\begin{array}{c}\text { The rapid rate } \\
\text { of } \\
\text { fermentation }\end{array}$ & $\begin{array}{c}\text { The apparent } \\
\text { rate of } \\
\text { fermentation }\end{array}$ & Color & $\begin{array}{c}\mathrm{O}_{2} \\
\text { measured }\end{array}$ & $\begin{array}{c}\mathrm{O}_{2} \\
\text { Total }\end{array}$ & Polyphenols \\
\hline $\begin{array}{c}15.2 \\
10.9\end{array}$ & 3.22 & 1.73 & 64.61 & 79.15 & 7.5 & 0.18 & 0.35 & 122 \\
\hline $\begin{array}{c}13.1 \\
10.41\end{array}$ & 3.43 & 1.95 & 65.58 & 78.75 & 8.0 & 0.10 & 0.20 & 120 \\
\hline $\begin{array}{c}11.5 \\
10.55\end{array}$ & 3.31 & 1.88 & 64.38 & 77.15 & 8.2 & 0.15 & 0.30 & 115 \\
\hline
\end{tabular}

Table-2, presents the analysis of finished beer with the original extract $15 \%, 13 \%$ and $11.3 \%$, but the blended - diluted beer with water (the amount of oxygen $0.002 \mathrm{mg} / 1$ ) in the extract of $10.5 \% .^{4}$

Also note:

i. Reduce the value of the rapid rate of fermentation and the apparent degree of fermentation, in all three cases.

ii. Alcohol in normal values for these extracts.

iii. $\mathrm{CO} 2$ content in the appropriate value.

iv. The color value is as required.

v. Measuring oxygen and dissolved in acceptable quantities.

vi. Polyphenols in an amount of about $120 \mathrm{mg} / 1$, acceptable.

Table-3: Analysis of Green Beer with Supplying Oxygen in amounts of $8 \mathrm{mg} / 1$.

\begin{tabular}{c|c|c|c|c|c|c}
\hline $\begin{array}{c}\text { The basic } \\
\text { extract }\end{array}$ & Really extract & $\begin{array}{c}\text { Visible } \\
\text { extract }\end{array}$ & $\begin{array}{c}\text { The rapid rate } \\
\text { of } \\
\text { fermentation }\end{array}$ & $\begin{array}{c}\text { The apparent } \\
\text { rate of } \\
\text { fermentation }\end{array}$ & Alcohol & $\mathrm{pH}$ \\
\hline$\%$ & $\%$ & $\%$ & $\%$ & $\%$ & $\%$ & $\%$ \\
\hline 15.6 & 5.95 & 3.66 & 63.8 & 76.54 & 6.51 & 4.43 \\
\hline 14.81 & 5.22 & 2.95 & 66.51 & 80.08 & 6.43 & 4.34 \\
\hline 11.51 & 3.68 & 1.82 & 69.27 & 84.13 & 5.13 & 4.23 \\
\hline
\end{tabular}

Table-3, presents the analysis of the green beer with the oxygen of $8 \mathrm{mg} / \mathrm{l}$, in fermentation. And note the rapid scale and visible to fermentation in nominal value, if we refer to the guidelines of the European Convention for beer. ${ }^{4,5}$

Table-4: Analysis of Beer Finished with Oxygen Amounts of $8 \mathrm{mg} / \mathrm{l}$.

\begin{tabular}{c|c|c|c|c|c|c|c|c}
\hline $\begin{array}{c}\text { The } \\
\text { basic } \\
\text { extract }\end{array}$ & $\begin{array}{c}\text { Really } \\
\text { extract }\end{array}$ & $\begin{array}{c}\text { Visible } \\
\text { extract }\end{array}$ & $\begin{array}{c}\text { The rapid rate } \\
\text { of } \\
\text { fermentation }\end{array}$ & $\begin{array}{c}\text { The apparent } \\
\text { rate of } \\
\text { fermentation }\end{array}$ & Color & $\begin{array}{c}\mathrm{O}_{2} \\
\text { measured }\end{array}$ & $\begin{array}{c}\mathrm{O}_{2} \\
\text { Total }\end{array}$ & Polyphenols \\
\hline$\%$ & $\%$ & $\%$ & $\%$ & $\%$ & EBC & $\mathrm{mg} / \mathrm{l}$ & & $\mathrm{mg} / \mathrm{l}$ \\
\hline $\begin{array}{c}15.6 \\
10.82\end{array}$ & 3.64 & 1.93 & 67.61 & 82.16 & 8 & 0.14 & 0.3 & 128 \\
\hline
\end{tabular}


RASĀYAN J. Chem.

Vol. 11 | No. 3 |1007 - 1017 | July - September | 2018

\begin{tabular}{l|c|c|c|c|c|c|c|c}
\hline $\begin{array}{l}14.81 \\
11.31\end{array}$ & 3.82 & 2.03 & 67.58 & 82.04 & 8.5 & 0.09 & 0.18 & 127 \\
\hline $\begin{array}{l}11.51 \\
11.11\end{array}$ & 3.74 & 1.98 & 67.66 & 82.17 & 8.4 & 0.13 & 0.27 & 124 \\
\hline
\end{tabular}

Table-4, presents the analyses of finished beer with extracts of $15 \%, 13 \%$ and $11.3 \%$, with the amount of oxygen of $8 \mathrm{mg} / \mathrm{l}$ in fermentation and noticed the following changes:

i. The expected value of real extract real and apparent extract,

ii. Also, the rapid and significant degree of fermentation,

iii. Alcohol in amounts appropriate for these values,

iv. Sufficient $\mathrm{CO}_{2}$,

v. Color value as expected,

vi. Good Grief

vii. Measuring oxygen and dissolved the good, and

viii.Polyphenols as expected ${ }^{3}$

Table-5: Analysis of Green Beer with Supplying Oxygen in Amounts of $10 \mathrm{mg} / \mathrm{l}$.

\begin{tabular}{c|c|c|c|c|c|c}
\hline $\begin{array}{c}\text { The basic } \\
\text { extract }\end{array}$ & Really extract & $\begin{array}{c}\text { Visible } \\
\text { extract }\end{array}$ & $\begin{array}{c}\text { The rapid rate } \\
\text { of } \\
\text { fermentation }\end{array}$ & $\begin{array}{c}\text { The apparent } \\
\text { rate of } \\
\text { fermentation }\end{array}$ & Alcohol & $\mathrm{pH}$ \\
\hline$\%$ & $\%$ & $\%$ & $\%$ & $\%$ & $\%$ & $\%$ \\
\hline 15.1 & 5.10 & 3.21 & 67.8 & 78.5 & 6.9 & 4.48 \\
\hline 13.2 & 4.80 & 2.75 & 69.5 & 81.2 & 6.8 & 4.32 \\
\hline 11.5 & 3.15 & 1.55 & 72.4 & 85.1 & 5.2 & 4.41 \\
\hline
\end{tabular}

Table-5, presents an analysis of green beer by oxygen injection in amounts of $10 \mathrm{mg} / \mathrm{l}$, in extracts of $15 \%, 13 \%$ and $11.3 \%$. From these results is shown an increasing quantity of apparent value and rapid degree of fermentation. ${ }^{1}$

Table-6: Analysis of Finished Beer with Oxygen Amounts of $10 \mathrm{mg} / \mathrm{l}$.

\begin{tabular}{c|c|c|c|c|c|c|c|c}
\hline $\begin{array}{c}\text { The } \\
\text { basic } \\
\text { extract }\end{array}$ & $\begin{array}{c}\text { Really } \\
\text { extract }\end{array}$ & $\begin{array}{c}\text { Visible } \\
\text { extract }\end{array}$ & $\begin{array}{c}\text { The rapid rate } \\
\text { of } \\
\text { fermentation }\end{array}$ & $\begin{array}{c}\text { The apparent } \\
\text { rate of } \\
\text { fermentation }\end{array}$ & Color & $\begin{array}{c}\mathrm{O}_{2} \\
\text { measured }\end{array}$ & $\begin{array}{c}\mathrm{O}_{2} \\
\text { Total }\end{array}$ & Polyphenols \\
\hline $\begin{array}{c}15.1 \\
11.0\end{array}$ & 3.52 & 1.95 & 68.15 & 83.1 & 7.8 & 0.18 & 0.29 & 129 \\
\hline $\begin{array}{c}13.2 \\
10.85\end{array}$ & 3.60 & 1.64 & 69.10 & 82.5 & 7.5 & 0.20 & 0.30 & 127 \\
\hline $\begin{array}{c}11.5 \\
10.51\end{array}$ & 3.48 & 1.72 & 71.25 & 83.0 & 8 & 0.17 & 0.28 & 122 \\
\hline
\end{tabular}

While at Table- 4 are given an analysis of finished beer with oxygen amounts of $10 \mathrm{mg} / \mathrm{l}$, in extracts of $15 \%, 13 \%$, and $11.3 \%$, and in this overview we see:
i. Reduction of real extract values
ii. Reduction of extract values significantly
iii. An increase of the rapid degree of fermentation
iv. Increasing the level of apparent fermentation

The values of alcohol, $\mathrm{CO}_{2}$, color, bitterness, and polyphenols are normal, and oxygen values are as given by the European Convention of beer. ${ }^{1,8}$

In the graph shown in Fig.-1, is presented the apparent scale of fermentation for the green beer, with extract $15 \%, 13 \%$, and $11.3 \%$. There is a low value of the apparent fermentation for the three extracts mentioned. ${ }^{8}$ 
RASĀYAN J. Chem.

Vol. 11 | No. 3 |1007 - 1017 | July - September | 2018

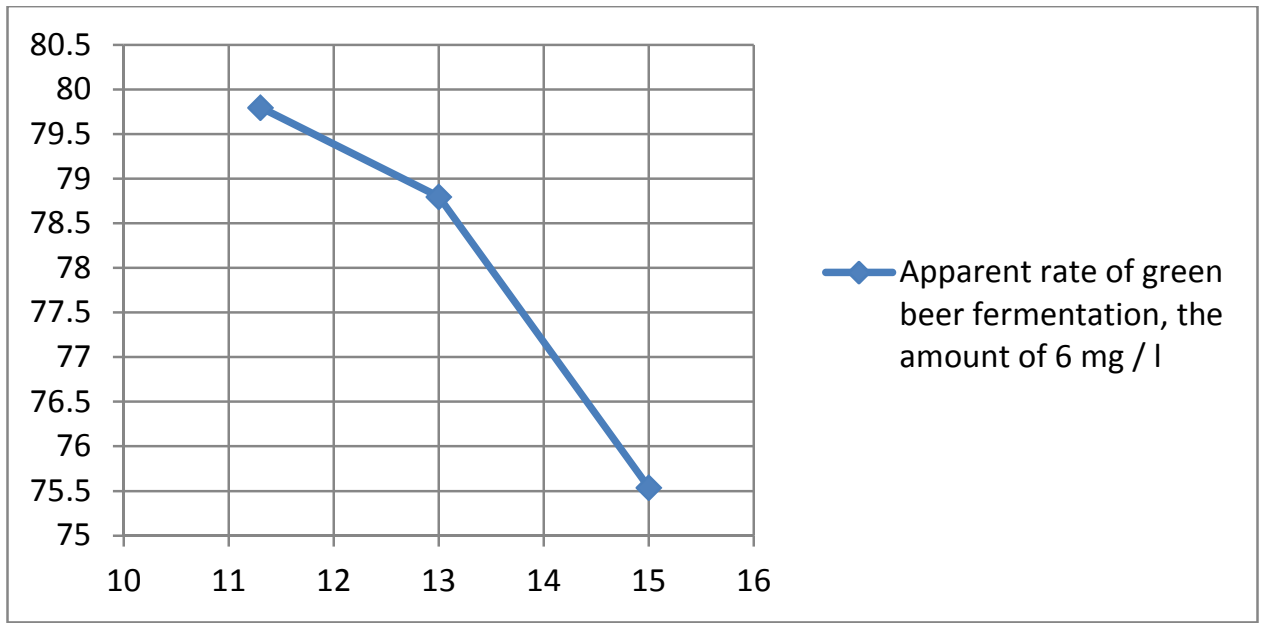

Fig.-1: the Apparent rate of green beer fermentation, the amount of $6 \mathrm{mg} / 1$ in extracts of $15 \%, 13 \%$ and $11.3 \%$.

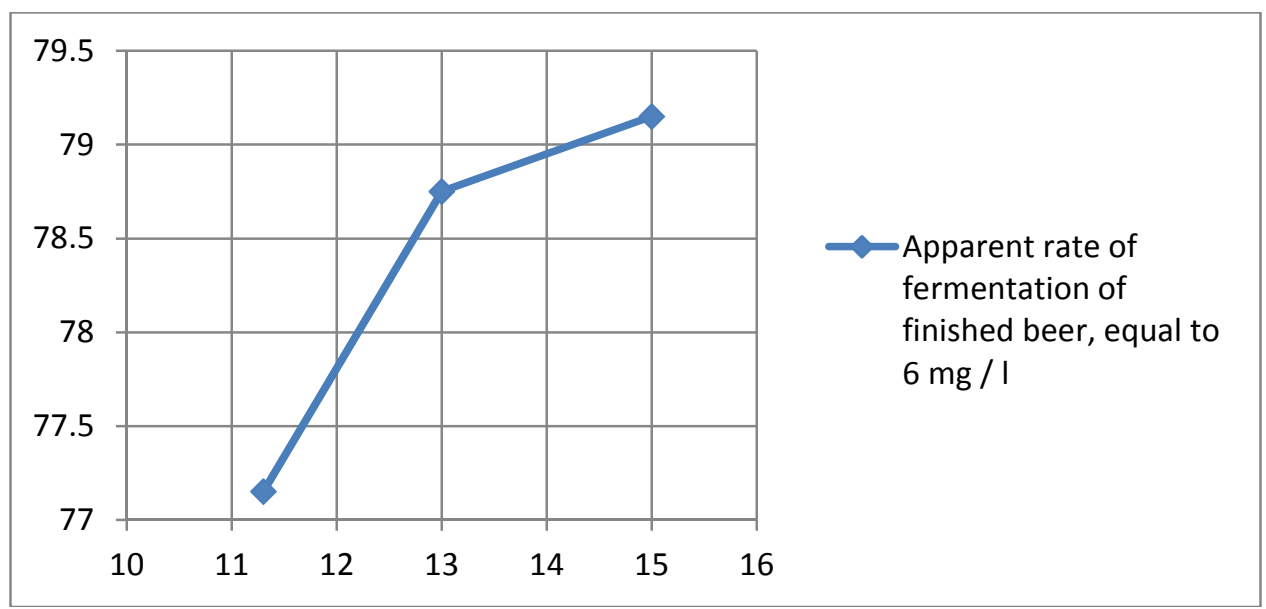

Fig.-2: the Apparent rate of fermentation of finished beer, equal to $6 \mathrm{mg} / 1$ in extracts of $15 \%, 13 \%$, and $11.3 \%$.

Figure-2, shows the apparent rate of fermentation diagram of the finished beer for the amount of oxygen 6 $\mathrm{mg} / \mathrm{l}$, and note:

i. For a beer with $15 \%$ extract, the apparent rate fermentation is $70.15 \%$,

ii. For a beer with $13 \%$ extract, the apparent rate fermentation is $78.75 \%$, and

iii. For a beer of $11.3 \%$, extract, the apparent scale fermentation is $77.15 \%$.

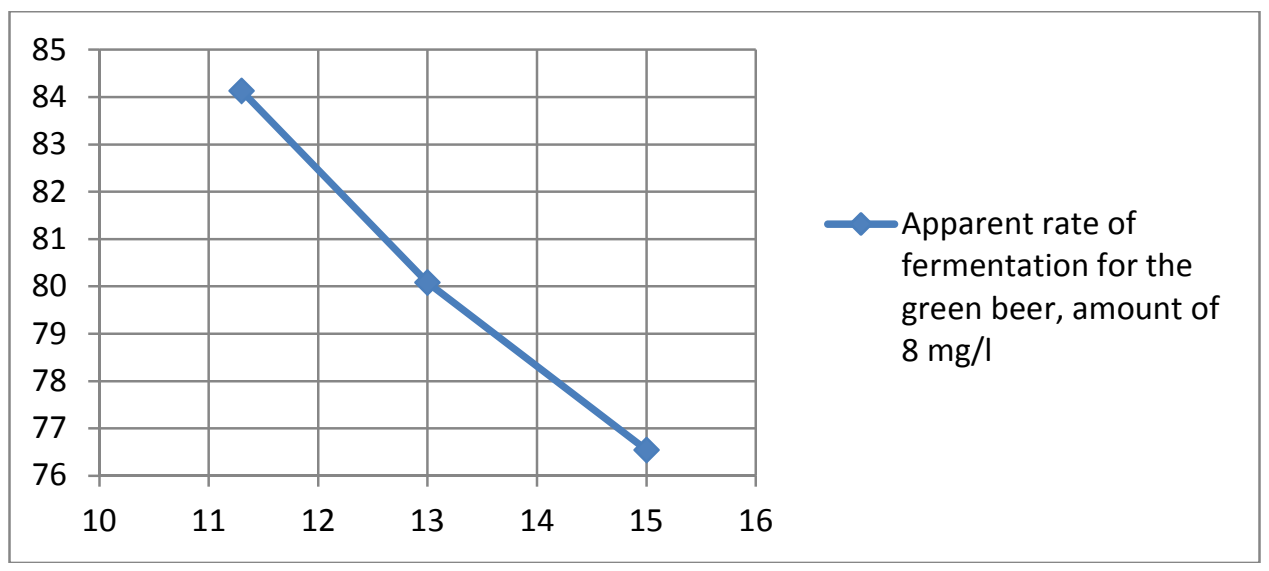

Fig.-3: the Apparent rate of fermentation for the green beer, amount of $8 \mathrm{mg} / \mathrm{l}$ in extracts of $15 \%, 13 \%$, and $11.3 \%$. 
Figure-3, the graph shows an apparent degree of fermentation of the green beer with extract of $15 \%, 13 \%$ and $11.3 \%$ and the amount of oxygen in the fermentation of $8 \mathrm{mg} / \mathrm{l}$.

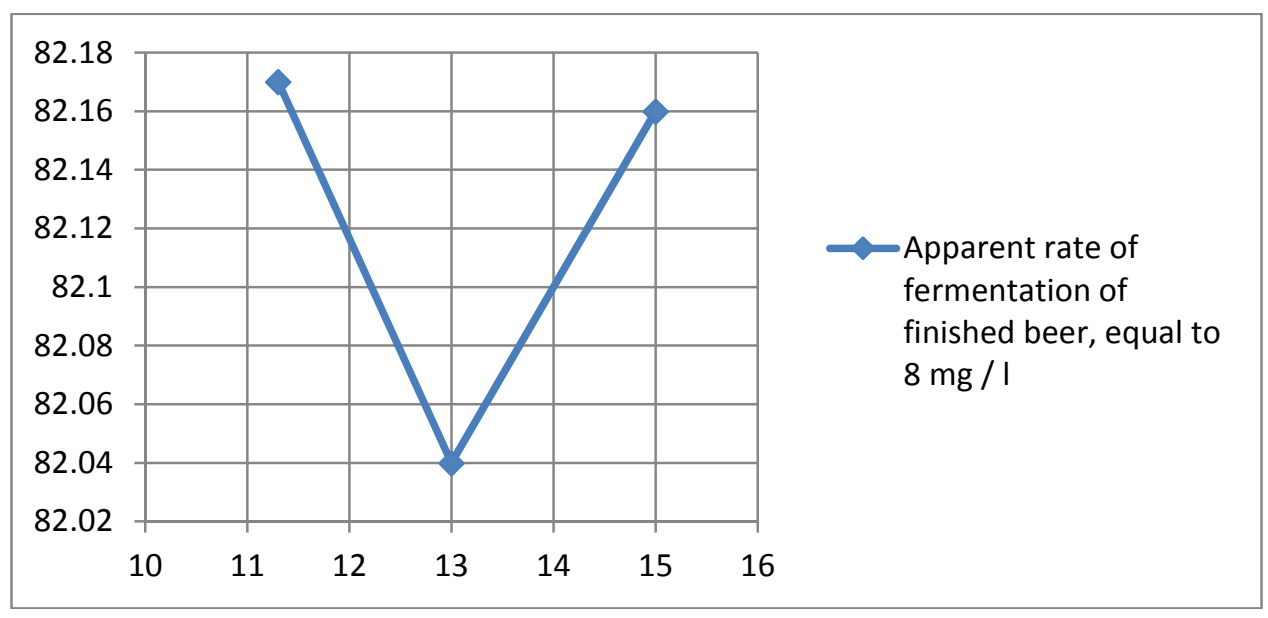

Fig.-4: the Apparent rate of fermentation of finished beer, equal to $8 \mathrm{mg} / 1$ in extracts of $15 \%, 13 \%$, and $11.3 \%$. At Fig.-4, the graph shows an apparent instance of finished beer with an oxygen amount of $8 \mathrm{mg} / 1$, with extracts of $15 \%, 13 \%$ and $11.3 \%$, and noted that:

i. Beer with $15 \%$ extract, has the apparent rate of fermentation $82.16 \%$,

ii. Beer with $13 \%$ extract has the apparent rate of fermentation $82.04 \%$, and

iii. Beer with $11.3 \%$ extract has the apparent rate of fermentation $82.17 \%$.

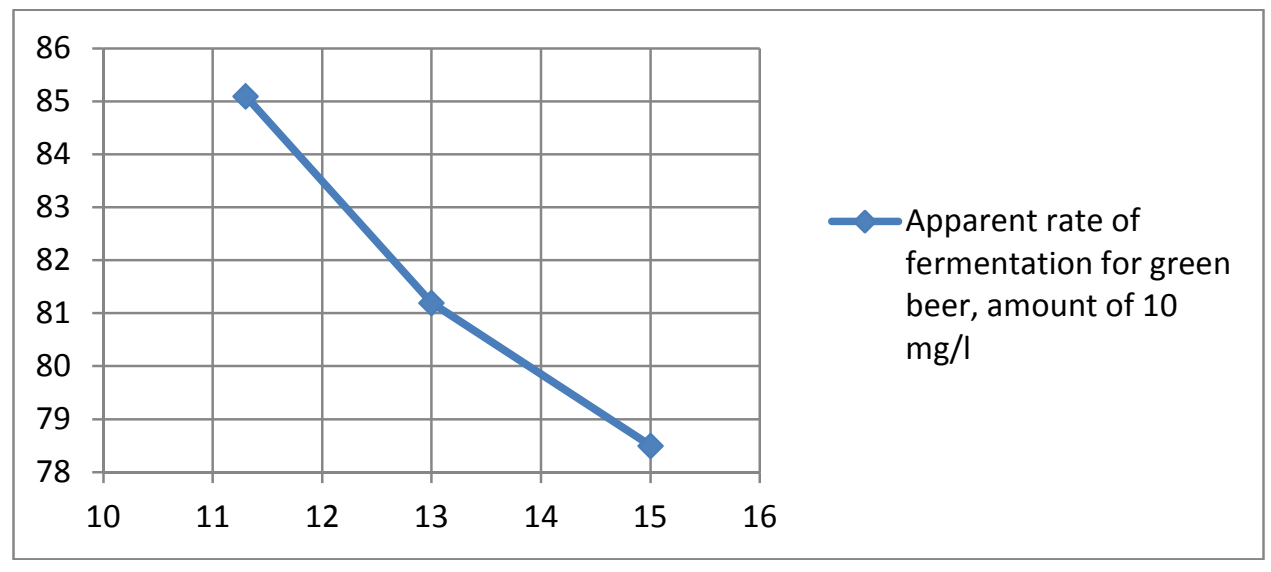

Fig.-5: the Apparent rate of fermentation for green beer, amount of $10 \mathrm{mg} / \mathrm{l}$ in extracts of $15 \%, 13 \%$ and $11.3 \%$.

Also in the Fig.-5 is given the graph of apparent degree for green beer, for the extract of $15 \%, 13 \%$ and $11.3 \%$, wherein the main fermentation was given oxygen in amounts of $10 \mathrm{mg} / 1 .^{7}$

Figure-6, presents the graph with apparent degree for beer fermentation with oxygen amount of $10 \mathrm{mg} / \mathrm{l}$, for a beer of $15 \%, 13 \%$, and $11.3 \%$ extract, and note:

i. For a beer with $15 \%$ extract is a significant rate of fermentation of $83.1 \%$

ii. For a beer with $13 \%$ extract, apparent fermentation rate of $82.5 \%$, and

iii. For a beer with $11.3 \%$ extract, a significant rate of fermentation of $83.0 \%$.

\section{Organoleptic Evaluation of Finished Beer}

In Table-7 are given the organoleptic results of samples of finished beer with $10.5 \%$ extract (taste, aroma, clearance, and foam) produced with different amounts of oxygen in fermentation. The results show that 
RASĀYAN $J$. Chem.

Vol. 11 | No. 3 |1007 - 1017 | July - September | 2018

samples with an oxygen content of $8 \mathrm{mg} \mathrm{O}_{2} / \mathrm{l}$, are evaluated with higher point score compared to other beer samples.

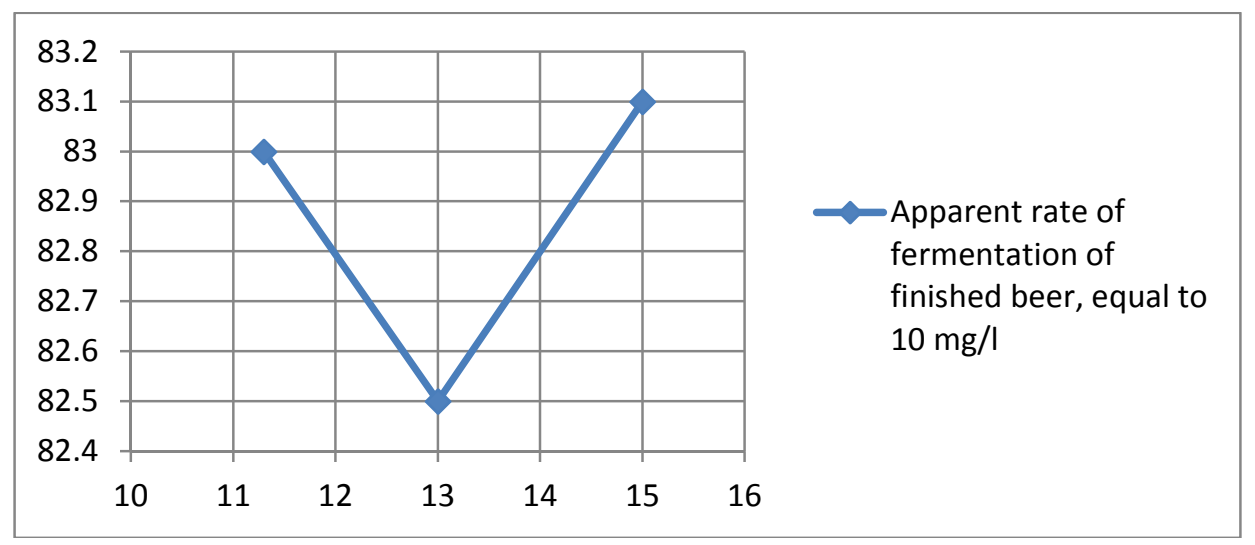

Fig.-6: the Apparent rate of fermentation of finished beer, equal to $10 \mathrm{mg} / \mathrm{l}$ in extracts of $15 \%, 13 \%$, and $11.3 \%$.

From the evaluation given in Table-7 is shown that sample with an oxygen content of $8 \mathrm{mg} \mathrm{O} / \mathrm{l}$ is evaluated higher from the degustation team.

Table-7: Organoleptic results for a finished beer with $10.5 \%$ extract

\begin{tabular}{|c|c|c|c|c|}
\hline & \multirow{2}{*}{\multicolumn{3}{|c|}{ Beer degustation }} & \multirow{4}{*}{$\begin{array}{c}\text { No. } \\
\text { Date: } \\
15.07 .2017 \\
\text { Maximum points }\end{array}$} \\
\hline & & & & \\
\hline \multirow{2}{*}{$\begin{array}{l}\text { Organoleptic } \\
\text { characteristics }\end{array}$} & \multicolumn{3}{|c|}{ Sample } & \\
\hline & $6 \mathrm{mg} \mathrm{O}_{2} / \mathrm{l}$ & $8 \mathrm{mg} \mathrm{O}_{2} / 1$ & $10 \mathrm{mg} \mathrm{O}_{2} / \mathrm{l}$ & \\
\hline Taste & 2.2 & 2.8 & 2.4 & 3 \\
\hline Aroma & 1.4 & 2 & 1.6 & 2 \\
\hline Color & 3.8 & 4.8 & 3.6 & 5 \\
\hline Clarity & 3.2 & 3.6 & 3.4 & 4 \\
\hline Foam & 5.6 & 5.8 & 5.6 & 6 \\
\hline Total points & 16.2 & 19 & 16.6 & 20 \\
\hline
\end{tabular}

At Table- 8 there are given organoleptic evaluation results of finished beer with $11.3 \%$ extract and with oxygen amount of 6,8 , and $10 \mathrm{mg} \mathrm{O}_{2} / 1$.

Table-8: Organoleptic Results for Finished Beer with 11.3\% Extract.

\begin{tabular}{c|c|c|c|c}
\hline \multicolumn{4}{c}{ Beer Degustation } & No. \\
\cline { 3 - 4 } \multicolumn{2}{c}{} & Date: \\
\hline \multirow{2}{*}{$\begin{array}{c}\text { Organoleptic } \\
\text { characteristics }\end{array}$} & $6 \mathrm{mg} \mathrm{O} / 1$ & $8 \mathrm{mg} \mathrm{O} / 1$ & $10 \mathrm{mg} \mathrm{O}_{2} / 1$ & Maximum points \\
\cline { 2 - 5 } & 2.4 & 3 & 2.4 & 3 \\
\hline Taste & 1.6 & 2 & 1.8 & 2 \\
\hline Aroma & 4.6 & 5 & 4.4 & 5 \\
\hline Color & 3.6 & 3.8 & 3.4 & 4 \\
\hline Clarity & 5.6 & 5.8 & 5.6 & 6 \\
\hline Foam & 17.8 & 19.6 & 17.6 & 20 \\
\hline Total points & &
\end{tabular}

And at Table-9, there are given organoleptic evaluation results of finished beer with $15 \%$ extract and oxygen amount of 6,8 , and $10 \mathrm{mgO}_{2} / 1$. 
RASĀYAN J. Chem.

Vol. 11 | No. 3 |1007 - 1017 | July - September | 2018

Table-9: Organoleptic Results for Finished Beer with $15 \%$ extract.

\begin{tabular}{|c|c|c|c|c|}
\hline \multirow{4}{*}{$\begin{array}{l}\text { Organoleptic } \\
\text { characteristics }\end{array}$} & \multirow{2}{*}{\multicolumn{3}{|c|}{ Beer degustation }} & \multirow{4}{*}{$\begin{array}{l}\text { No. } \\
\text { Date: } \\
15.07 .2017 \\
\text { Maximum points }\end{array}$} \\
\hline & & & & \\
\hline & \multicolumn{3}{|c|}{ Sample } & \\
\hline & $6 \mathrm{mg} \mathrm{O}_{2} / 1$ & $8 \mathrm{mg} \mathrm{O}_{2} / \mathrm{l}$ & $10 \mathrm{mg} \mathrm{O}_{2} / 1$ & \\
\hline Taste & 2.6 & 2.8 & 2.6 & 3 \\
\hline Aroma & 1.6 & 1.8 & 1.6 & 2 \\
\hline Color & 4.6 & 4.8 & 4.4 & 5 \\
\hline Clarity & 3.6 & 3.8 & 3.4 & 4 \\
\hline Foam & 5.4 & 5.6 & 5.2 & 6 \\
\hline Total points & 17.8 & 18.8 & 17.2 & 20 \\
\hline
\end{tabular}

\section{CONCLUSION}

Considering the high impact that oxygen has regarding the quality of beer (alcoholic fermentation, taste, consistency, shelf life), because of reactions it may have with a number of its compounds and its ingredients, this study is oriented for very careful determination of necessary and needed amounts of oxygen for different processes in beer production.

Analyzing step by step its role, starting from wort, than in matured beer, filtration, under pressure tanks and fillers, there are given these conclusions:

1. Different amounts of oxygen injecting in the wort for beer fermentation, have different impacts and in the wort of $10.5 \%, 11.3 \%$, and $15 \%$ extract, there are these conclusions:

- At the oxygen amount of $6, \mathrm{mg} \mathrm{O}_{2} / \mathrm{l}$ happened slow fermentation and values of the real and apparent extract are higher. From slow fermentation are formed undesirable compounds in beer, for example, the values of diacetyl are grown. And fermentation went slowly and fermentation degree is lower.

- At the oxygen amount of $8 \mathrm{mg} \mathrm{O} / \mathrm{l}$ the fermentation process went well. Fermentation lasted 7 days and is gained beer with desired characteristics, such as: longer shelf life, with a good consistency of taste even after six months, good clearance of beer, and a stabile foam beer.

- At the oxygen amount of $10 \mathrm{mg} \mathrm{O} / 1$, the real extract and apparent extract have lower values, but fermentation degree has given higher values. Therefore, with this amount of oxygen the fermentation is faster and the growing of yeast is higher, and the taste of the beer was not so good and not so good beer stabilization in additional fermentation.

2. It is analyzed the finished beer with different amount of oxygen and in beer with different extract:

- $0.6 \mathrm{mg} / \mathrm{l}$; it is gained not so stabilized beer that has lost the taste and freshness by the time. With this amount of oxygen, there is stabilized beer in taste until one month, because of the maillard reactions. And as a consequence of higher oxygen content, the intensity of the color is raised in an undesirable way.

- $0.3 \mathrm{mg} / \mathrm{l}$, is gained average good taste, with six months shelf life.

- The oxygen amount of $0.1 \mathrm{mg} / \mathrm{l}$, resulted in the best in consistency, freshness, stability and beer shelf life.

As the conclusion of this study is that there is proved what are the best oxygen quantities that should be used for beer production, its standardization to reach the optimal results in beer production and to improve the quality of the beer.

Monitoration of oxygen quantities, substitution with carbonic gas and deaerated water in the production process, resulted to the production of stabilized good taste beer and color for at least one year time. 
RASĀYAN J. Chem.

Vol. 11 | No. 3 |1007 - 1017 | July - September | 2018

\section{Recommendation}

At the wort production process, to avoid oxygen intake:

i. In sense of avoiding oxygen intake at the wort production process, the wet and conditioning milling should be processed in 45 minutes.

ii. The velocity of mixing in the phase of mash heating should not exceed $4 \mathrm{~m} / \mathrm{s}$.

iii. Entering of mash in the lautering tank should be from the bottom and slowly.

iv. The time of mash boiling should not exceed 80 minutes.

At fermentation process:

i. At fermentation, oxygen injection should be at amount of $8 \mathrm{mg} / \mathrm{l}$.

ii. Filling of fermentation tanks, CCTs should be as soon as possible and not longer than 18 hours.

Maturation time:

i. Before filling the tank with green beer for maturation, the tank should be filled with carbonic gas with the pressure not less than 0.20 bars.

ii. Beer transportation at the end of maturation should be with deaerated water.

iii. Emptying of the maturation tank should be done by pushing with carbonic gas.

Filtration process:

i. Filter preparation should be done with deaerated water.

ii. Entering kieselguhr in filtration process should always be done in presence of carbonic gas.

iii. Beer at the end of the filtration process should be transported with deaerated water.

Tanks under pressure:

i. Tanks under pressure should always be under pressure of the carbonic gas above 0.5 bars.

ii. Their emptying should be done always by pushing with carbonic gas.

iii. Pushing to beer filler should be done with deaerated water.

Beer filler:

i. Preparation of beer filler should always be with deaerated water.

ii. Before beer filling of bottles should be injected carbonic gas in the bottle to put out the air from the bottle and to ensure filling counter pressure with carbonic gas.

iii. Proper closing closure of bottles to avoid gas leaking.

\section{REFERENCES}

1. Atheel H. Alwash, Dhuha H. Fadhil, Ali Abd Ali, Rasayan Journal of Chemistry, 10(3),922(2017), DOI: $10.7324 /$ RJC.2017.1031632

2. C. Rambabu, G.Ramu1, A. Biksham Babu and S.Venkata Rao, Rasayan Journal of Chemistry, 3(4), 777(2017)

3. EBC, F. (1999), Manual of Good Practice, Vol.12, Quality. Nurnberg: Fachverl. Carl. 15, 16, 17.

4. EBC, F. (2001), Manual of Good Practice, Vol. 7, Fermentation and Maturation. Nurnberg. 11-82.

5. EBC, F. (2001), Manual of Good Practice,. Vol.11, Brewery Effluent. Nurnberg. 23,27.

6. EBC., F. (1999), Manual of Good Practice, Beer Filtration, Stabilision and Sterilization. Nurnberg: Fachverl.Carl.16,17

7. EBC., F. (2010), Analytica EBC, Nurnberg. 9,11,12.

8. W. Kunze(2004), Brewing and Malting, Berlin: VLB, pp. 18-152.

9. M. M. Kadhim, A.N. Aldujaili and M.H. Homady, Rasayan Journal of Chemistry, 10(2),305(2017), DOI: $10.7324 /$ RJC.2017

10. Master Brewers Associations of the Americas (MBAA), Technical Quarterly, 45(4), 352(2008), DOI:10.1094/TQ-45-4-0352

11. MEBAK, (2002), Brautechnick Untersuchusmethoden, Freising-Weihenstephan: Mebak, pp. 222326. 
RASĀYAN J. Chem.

Vol. 11 | No. 3 |1007 - 1017 | July - September | 2018

12. MEBAK, (2013), Brautechmischer Analysemethoden. Band 2: Wurce, Bier und Biermischgentrink. Freising-Weihenstephan: Mebak, pp. 486-515.

13. Richa Saxena and S. C. Bhatt, Rasayan Journal of Chemistry, 10(4),1340(2017), DOI: 10.7324/RJC.2017

14. White Chris., Zainasheff Jamil., (2010), Yeast the Practical Guide to Beer Fermentation, USA: Kristi Switzer, pp. 12-28.

[RJC-3087/2018] 